\title{
The Initiative IdeiaSUS and the Perspectives of a Collaborative Network: For an Ecology of Locoregional Knowledge
}

\author{
Fernandes VR, Coelho de Amorim A*, Vicente da Silva JP, Sergio JV, Filho \\ EC, Carrera JL, Le Cocq C, Magalhaes M, Machado K and Mariano G \\ The Oswaldo Cruz Foundation, Brazil
}

*Corresponding author: Annibal Coelho de Amorim, The Oswaldo Cruz Foundation, Fiocruz's Presidency Chief of Staff/IdeiaSUS, Av. Brasil 4365, Mourish Castle, 5th Floor, Manguinhos, RJ, Brazil, Email: annibalamorim.fiocruz@gmail.com

\section{Research Article}

Volume 3 Issue 1

Received Date: January 28, 2020

Published Date: February 24, 2020

DOI: $10.23880 /$ jqhe- 16000153

\section{Abstract}

This is a paper about IdeiaSUS, an Oswaldo Cruz Foundation's initiative associated with CONASS \& CONASEMS, two health secretaries organizations of nationwide, which attempts to focus on a theoretical framework to structure a collaborative network of practices and experiences within SUS, the Unified Health System of Brazil.

Our intent was to address how a comprehensive methodology might help tangible local knowledge emerge as a territorial innovation by fostering social mobilization, with the purpose of characterizing whether these arrangements converge to what is called a community of practices.

The authors emphasize that the existence of IdeiaSUS/Fiocruz as a collaborative platform opens new perspectives for the analysis and systematization of registered practices, as well as the establishment of curatorships in collaboration with academic consortia and partners of Fiocruz/Conass/Conasems, which in recent years has promoted the discussion of health practices by professionals and managers in SUS.

Keywords: Community of Practices; Collaborative Platform; Local Knowledge; Health Curatorship

\section{Introduction}

"We conducted the health reform that created SUS, but its core, dehumanized and medicalized, is wrong. We need to understand this model and change it. What is its foundation? First, the promotion of health, and not diseases. SUS has to first assess what is happening in people's daily lives and find out how we can interfere to make them healthier".

As from the 1970s, especially after the implementation of the Integrated Health Actions (Ações Integradas de SaúdeAIS), in 1982, the Brazilian health system was the subject of a broad and intense process of changes that resulted in the institutionalization of the Unified Health System (SUS) in the Federal Constitution from 1988. We highlight the VIII National Health Conference, in 1986, whose final report affirmed the principles that guide the modern Brazilian Health Reform.

The creation of SUS resulted basically from two interconnected factors: the health system crisis-with a chronic deficit of resources and inability to respond to the deterioration of the population's health conditions, in the context of the structural economic crisis affecting the country; and the process of fights waged by the Health Reform Movement in the context of the redemocratization of Brazilian society, which was strengthened in the first half of the 1980s. 
The Health Reform Movement had as its central objective transforming the health system, in view of the importance of public health policy for the construction of a fairer, more democratic and solidary society. The health system was historically recognized for its ineffectiveness and inefficiency in addressing the population's health problems. It was characterized by its essentially curative profile, focused on curing diseases to the detriment of prevention and health promotion and of a hospital-centric character, with emphasis on medical-hospital, private and excluding care.

Another central characteristic of the old system was its imperviousness to the participation of society in defining its course and in controlling the use of resources for its financing.

The implementation of SUS represented a milestone in the history of health policies in our country, because health care has been legally assured as a right of citizenship to all Brazilian people since then. Prior to the promulgation of Federal Constitution, and the subsequent regulation of $L e i$ Orgânica da Saúde, LOS, in 1991 (Laws 8.080 and 8.142), access to health services and actions was legally guaranteed only to taxpayers of the pension system.

However, beyond universal access, the implementation of SUS sought to overcome the historical dichotomy between preventive and curative services, and the shift from the emphasis on individual care to the emphasis on disease prevention and health promotion, from the perspective of comprehensive health care. The objective was also to democratize the system with the decentralization of management and the participation of users and health workers in decision-making and control of services.

Thus, amidst a profusion of virtual strategies of the third millennium, we are invited to better understand the role of establishing local networks. According to Zygmunt Baumann, [1], they are opposed to the advance of "globalization and human consequences", which we will address later.

Seen that, when describing IdeiaSUS/Fiocruz as a collaborative network of locoregional practices and its methodology of rounds of conversation (thematic or not), we sought support in theoretical and conceptual aspects that tangible local knowledge as a territorial innovation and social mobilization, with the purpose of characterizing whether or not these arrangements converge to what is termed a community of practices (CoP).

Just like we highlight above, among the aspects addressed in the present article, the principles of SUS and health reform in its interface are our starting point, along with the Sustainable Development Goals (SDGs) and the
2030 agenda, exemplifying how these communities of local practices are able to establish intervention processes from the reality evidenced by subjects that are entitled to their health rights [2].

Finally, we emphasize that the existence of IdeiaSUS/ Fiocruz as a collaborative platform opens new perspectives for analysis and systematization of registered practices, as well as the establishment of curatorships in collaboration with academic consortia and partners of Fiocruz/Conass/ Conasems, which in recent years has promoted the discussion of health practices by professionals and managers in SUS.

\section{From The Origin of Ideiasus/Fiocruz and the Strategic Partnership with Conass \& Conasems}

IdeiaSUS, initially conceived as a "system of practices" in the management of Fiocruz's Vice Presidency for Environment, Health Care and Health Promotion 2009-2016, has gained a more definite shape over the last three years. This was done particularly by establishing a partnership with the National Council of Health Secretaries (Conselho Nacional dos Secretários de Saúde - CONASS) and the National Council of Municipal Health Secretaries (Conselho Nacional dos Secretários Municipais de Saúde - CONASEMS), which in its congresses highlight the practices of care and management with the exhibition."

Therefore, the initial conception of a repository or database of health \& environment practices within the Unified Health System gave rise to an even wider mosaic of practices, in which different categories started to gain due prominence in the fields of both health care and management, as shown in the figure below Figure 1 .

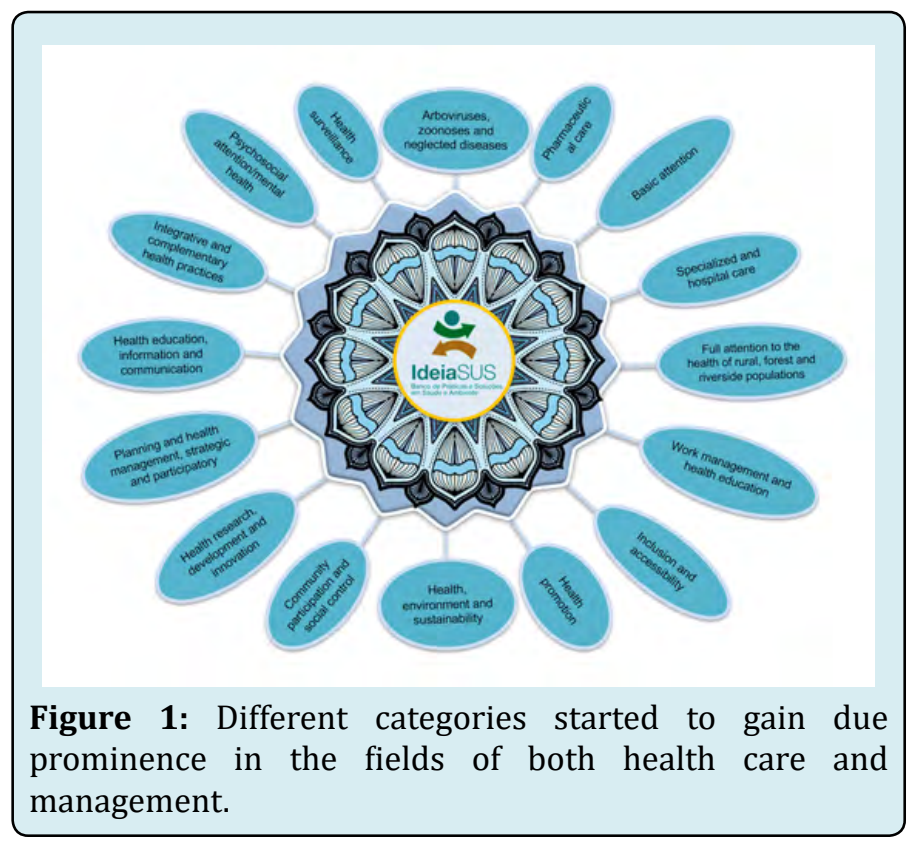


Consistent with Fiocruz's mission, IdeiaSUS (Health and Environment Bank for Practices and Solutions), created in 2013, is an initiative of technical cooperation between the Oswaldo Cruz Foundation (Fiocruz), the National Council of Health Secretaries (CONASS) and the National Council of Municipal Health Secretaries (CONASEMS), within the SUS Strategic Management Support Network.

Coordinated by the Fiocruz Presidency, the IdeiaSUS Platform, based on an executive project, defines as its general objective:

"Developing a collaborative platform, aiming to contribute to the identification, registration, mapping, systematization, dissemination and reapplication of innovative practices and solutions for SUS in the various territories of the country, with the development and integration of virtual collaborative networks and places for management in knowledge networks in health and environment, with the ethical-political purpose of strengthening the Unified Health System-SUS".

At the same time, it defines as its second general objective the perspective of:

"Producing, spreading and sharing knowledge and technologies aimed at strengthening and consolidating the Unified Health System (SUS), which contribute to the health promotion and quality of life of the Brazilian population for the reduction of social inequalities and the national dynamics of innovation, with the defense of the right to health and broad citizenship as its core values."

Bearing this in mind, supported by the IdeiaSUS Platform Terms of Reference and the Cooperation Agreement between Fiocruz, Conass and Conasems, we must broaden the theoretical-conceptual scope that has sustained our initiatives, the reason why we decide to undertake the present literature review.

Starting from the operational definition of community of practices, we open ourselves to a range of concepts that limit some of our ethical-political principles. This was done after searching for articles on this topic, with "the formation of groups of people who share common knowledge and are able to spread and develop new knowledge" as its starting point.

The authors Machado LP, et al. [3] refer to Wenger's (1991) initial concept in which CoPs are defined as "physical or non-physical groupings of people, which, for a common purpose, come together to share, commune and socialize experiences about a certain object," in which community is the central element of a CoP, composed of individuals, their interactions and the building of relationships."

On the other hand, practice "can be understood as knowledge shared by members (including a set of structures, tools, information, styles, language, stories, documents, and understanding shared by members)" Takimoto Tatiana [4].

Then we ask: How can we distinguish whether a practice inserted in the IdeiaSUS Platform has a collaborative profile or character?

On many occasions, a well-meaning group of professionals develops a particular practice in service or even in community, but what distinguishes it as a community of practice is its ability to build relationships of sharing with other professionals outside its group, or with system users. If there is no predisposition to socialize experiences on a theme, this group or community does not have a core characteristic of the concept we are committed to strengthen, one in which the community/group of practices really opens to collaborative efforts.

Another aspect is related to the concept of community of practice that we postulate. In addition to its collaborative character, this community must embrace the principle of the ecology of knowledge [5] which allows sharing experiences of scientific and popular/traditional knowledge.

A properly organized practice at the institutional level, may represent, strict sense, a set of professionals with expertise. However, if these institutional experiences are not allowed to be crossed by knowledge that derives, for example, from traditional/ancestral knowledge, we cannot characterize it as a community of practices with a collaborative profile.

In other words, participation characteristics that maintain their values as unique can be observed in a community. In opposition to this kind of participation, we observe those communities whose practices are permeated by inclusive principles of social mobilization [6], taking as an example the experiences of surveillance and environmental monitoring of vector control of arboviruses. These communities, besides being open to scientific knowledge, "bring to rounds of conversation" their knowledge of territorial [7] and existential cartography, important aspects that lead authors to call them sociotechnical networks [8], whereas others prefer to assign the terminology social technology to these experiences of territorial base [9].

As we can see, there are several nuances in this conceptual field. Hence, conceptual variation tenuously depends on how individuals behave within and outside the group, even depending on the individual characteristics of the leaders who participate in this or that community of practices. 


\section{Revisiting Theoretical Aspects That Cross the Collaborative Platform of IdeiaSUS}

Faced with globalization, Baumann, et al. [1] defines that an extraterritorial character has been gradually transforming life in many communities/localities. It is a Baumann's warning: "Being local in a globalized world is a sign of deprivation and social degradation [...] since, "[...] localities are losing their ability to generate and negotiate meanings and become dependent on actions that give and interpret meanings [...]" (pp: 8-9).

According to Zygmunt Baumann, [1], there was an "inexorable [...] displacement of decision centers [...] free from territorial restrictions-the restrictions of locality [...]," bringing to the contemporary scenario clashes of the so-called "modernity" imposed on those who are the immemorial curators of local "ancestry". As a consequence, what we see are states organized to respond to "appeals of modernity", leaving "literally aside" values and principles of the oral history of traditional peoples, who are expropriated from their local knowledge, "[...] reducing difference and alterity by force [...]" (pp: 12).

The recent examples of insurgency [10] in Ecuador by the community (of practices) of Indians threatened with the expropriation of their basic rights represent a breath of hope against the neoliberal waves that use the Latin American continent as a "test tube". Briefly, the "localities" imposed a defeat on the greedy "globality" of international capital, securing victory that is of the symbolic order, keeping alive the values of "community" (Gemeinschaft) and alterity [1], as opposed to the precepts imposed on them by the "association" (Gesselschaft).

Many other examples from other communities (quilombolas; African descent religious practices) face the same risk that Ecuadorian and native Indians of the Brazilian Amazon face from having their alterity denied by erasing the visibility of their ancestral heritage, their local customs and practices [11].

A phenomenon of visible ${ }^{11}$ order seems to reinforce the opposition pair of "global" versus "local", shifting our argument to the so-called "virtual networks" [12], which includes IdeiaSUS, the Health and Environment Bank for Practices and Solutions and Fiocruz/Conass/Conasems partnership.

In this regard, we rely on Baumann [1] and Levy P [12] to outline some aspects that we consider important for the central object of this article: "For an ecology of locoregional knowledge."
Baumann, [1] points out that "among all the technical factors of mobility, a particularly important role was played by the transport of information [...] which does not involve the movement of living bodies [...], bringing those far away closer, and, we add, distancing those who are close in locoregional practices. We will return to this last aspect later.

True to the title of his book, Baumann demonstrates that one of the consequences is "impact on social interaction," sometimes promoting associations and dissociations. The author uses Timothy W. Luke to reiterate ${ }^{1}$ that "[...] the specialty of traditional societies is organized around the capabilities of ordinary human bodies, leaving aside [...] conflict face to face, hand-to-hand combat, shoulder-toshoulder solidarity, face-to-face community, arm in arm friendship and step-by-step change [...]" (pp: 23-24).

As Zygmunt Baumann [1] has stated: "emancipated from the natural restrictions of the human body" (pp: 24). Assimilating Baumann's metaphor: in the presence of software, hardware, and wetware, everything gradually liquefies into something else, non-communal, non-local, essentially global, artificial, unnatural. In this sense, according to the philosopher Zygmunt Baumann, [1], "the distinctions here and there mean nothing else," or deepening in his analysis, "some may move out of the locality [...] whereas others helplessly observe the only locality they inhabit moving under their feet [...]" (pp: 25).

Simply put: while some have the false sense of being everywhere, most have the distinct feeling "without a place to call their own."

And what about the practices of your community? If there is no locality, what about the territory that makes up various localities? If everything liquefies, how can we continue to pass on oral history and its customs?

Everything Baumann ${ }^{1}$ defines as "certain community/ locality generating meanings," "have little chance of breaking free to move elsewhere" (pp: 25).

Given the prediction that we are facing the "incorporeality", we need to address the virtual networks from Pierre Levy, [12]: we highlight the concept of virtuality, that "[...] is not opposed to the real, but to the current [...] is a ghostly real, latent [...] derives from the medieval Latin virtualis, derived from virtus, strength, power [...] it does not exist in act [...] it is a mutation of identity, a displacement of the center [...]" (pp: 15-17).

According to Levy, [12], one of "its main virtualization modalities are the detachment of the here and now [...] 
the virtual, very often, is not present [...] its elements are nomadic, dispersed [...]" (pp: 19).

In the subtitle, Levy, [12] emphasizes virtualization as a kind of exodus, something that is in permanent motion, being everywhere in the network and at the same time nowhere, deterritorialized as it were, a concept that goes towards the position expressed by Baumann previously, the loss of locality, or in Levy's words, of your locality/location.

Being in cyber space belongs to all points but is not located here or there, reason that brings us to the previous statement that, although many are convinced that they are approaching those who are very distant, this truth is even more current when we realize that those of "your locality"equally dispersed at points of the network-are far further than we may suppose.

How do we "operate" and "feed" a cyber-platform, which among other functions should provide interactions of locoregional practices? Many will find this question too philosophical. Nonetheless, we will use its methodological power to make it clear that IdeiaSUS work processes can map and arrange meetings of communities of practices, which we will look more closely at in the next segment.

When subjected to a logic that continually distances exchanges at the local level, as professionals who make up the IdeiaSUS team, we must think globally but act wherever possible at the local level. This can be done by holding thematic meetings, conversation rounds, curatorship training, articulations with new strategic actors, participation in seminars and congresses with the purpose of establishing points of intercession with both Municipal and State Health Secretariats, etc.

In retrospect, we can highlight that the number of registered practices increases exponentially when some of the activities mentioned above are part of a strategic planning, either at the institutional level or in the relationship with partners from Conass and Conasems.

Although we have a cyber-platform, we emphasize that it is at the level of relationships and personal exchanges between professionals and managers that work will be better distributed at the locoregional level.

\section{About the IdeiaSUS' Strategies: For an Interface with the 2030 Agenda}

There may be many strategies to be exemplified in strengthening IdeiaSUS, including the development of mobile applications; an editorial line in partnership with Academic Consortia; locoregional training of technical personnel to decentralize the process of curating practices; and workshops and/or thematic rounds of conversation with strategic support from Conass and Conasems, etc.

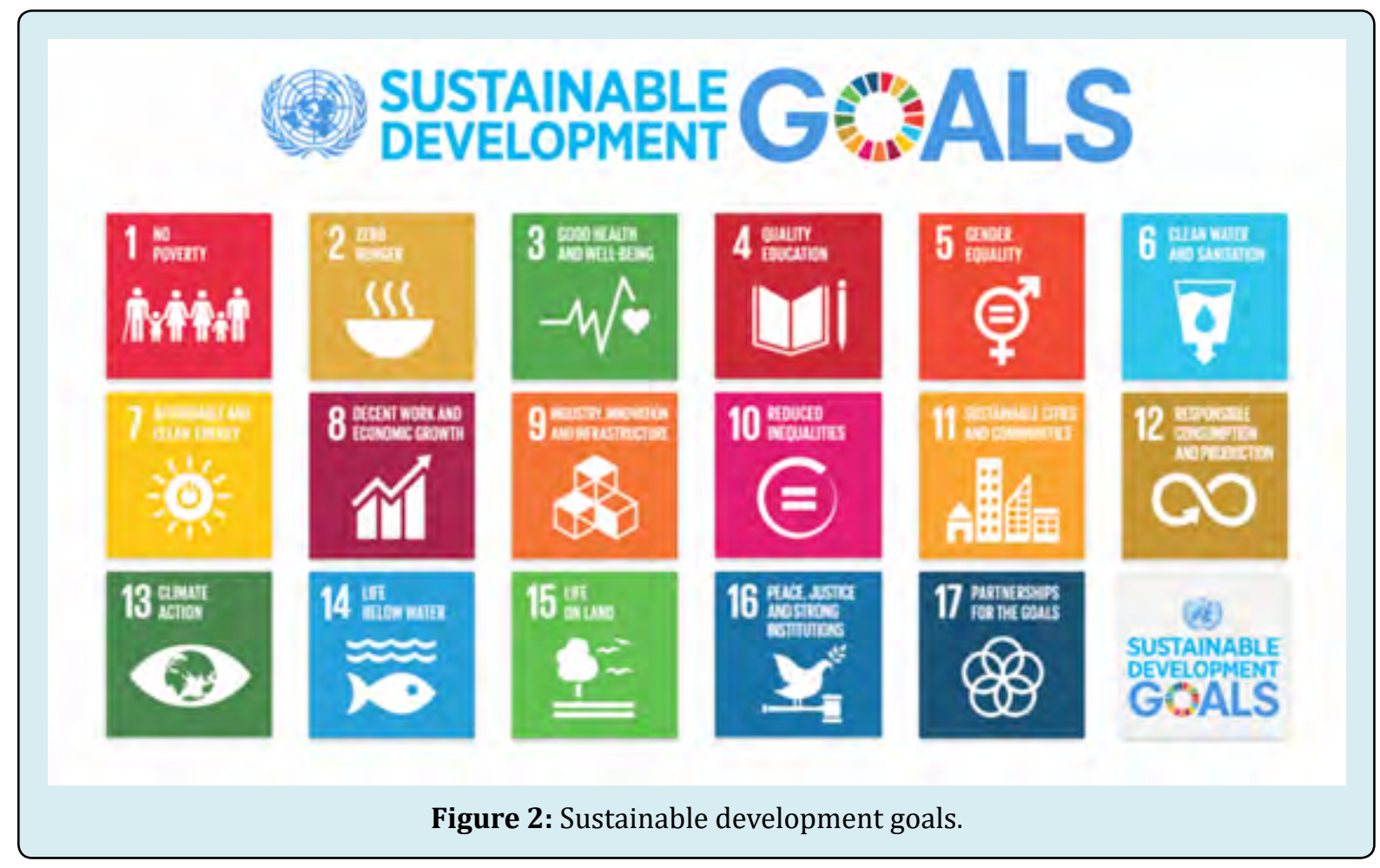


However, in the face of increasing social inequalities and iniquities and the hold of funds, such as in the field of Health, Science and Technology, the establishment among our programmatic and operational priorities urges choosing some of the 2030 [13] Agenda Goals (as to the SDGs flowchart below) and engaging them with a set of initiatives from the Fiocruz/Conass/Conasems partnership.

If, for instance, we choose 03 SDG goals from the flowchart below and focus our efforts to work in network over the next 3 years, we can map territorial based experiences and practices that aim to implement sustainable development in a systemic way from the practices recorded in our Health and Environment Bank for Practices and Solutions Figure 2.

By choosing, for example, three SDGs, number 3 (good health and well-being); 6 (clean water and sanitation) and 11 (sustainable cities and communities) and use them to structure IdeiaSUS workshops and thematic rounds in the main capitals-in which Fiocruz has decentralized units-we could encourage the registration of new practices related to these goals and, at the same time, systematize those practices structured with sustainability indicators that can be reapplied in other locations.

A search in our Health and Environment Bank for Practices and Solutions (see the table below) shows us the following distribution of practices registration under the "health" category axis in several subcategories. Observe the percentage of 20.61 practices registered under the heading "Goals of Sustainable Development in Health" Figure 3.

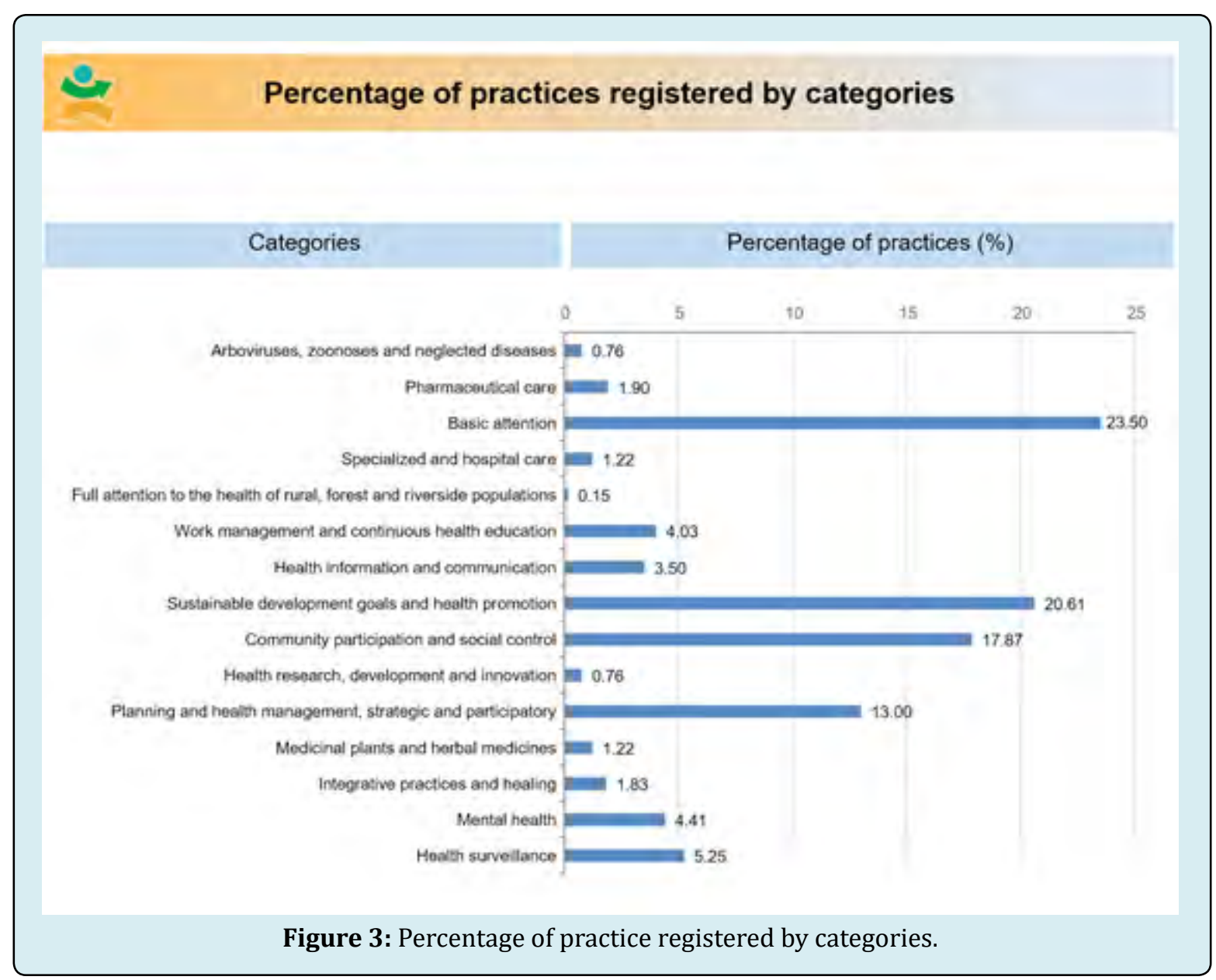

If we apply other filters (e.g., distribution of these SDG and Health practices by region) we may gather valuable information for publicizing sustainable practice indicators in our country (see chart below) Figure 4. 


\section{Graph of percentage of practices registered by region and state in Brazil}

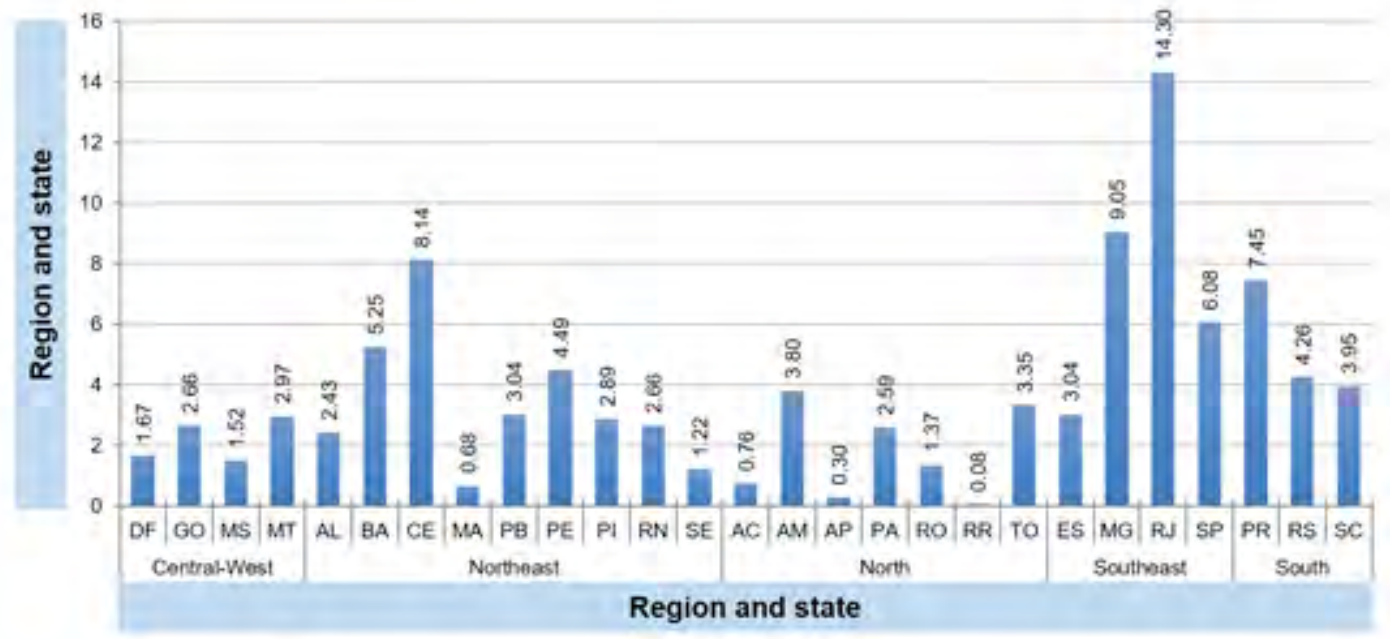

Figure 4: Graph of percentage practice register by region and state in Brazil.

When we examined the Strategic Studies Center (Centro de Estudos Estratégicos - CEE) Research Report about SDGs regarding respondents to the electronic questionnaire used for data collection (sent between January $22^{\text {nd }}, 2018$ and February $9^{\text {th }}, 2018$ ), which contained closed and open questions and analyzed the $2030^{13}$ Agenda, we found interesting public data that could be used in IdeiaSUS Locoregional Workshops (see figures from the CEE Report, page 9) (Figures $5 \& 6$ ).

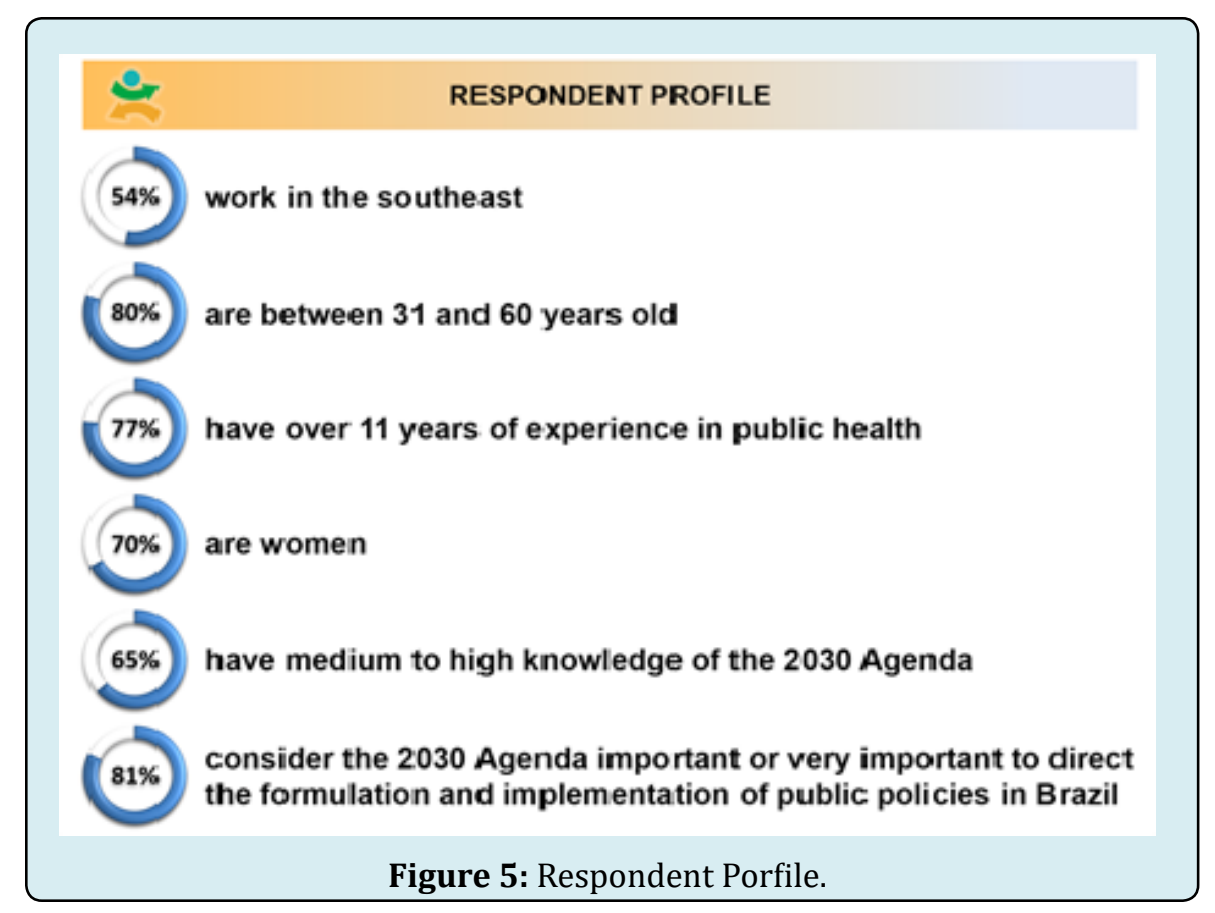




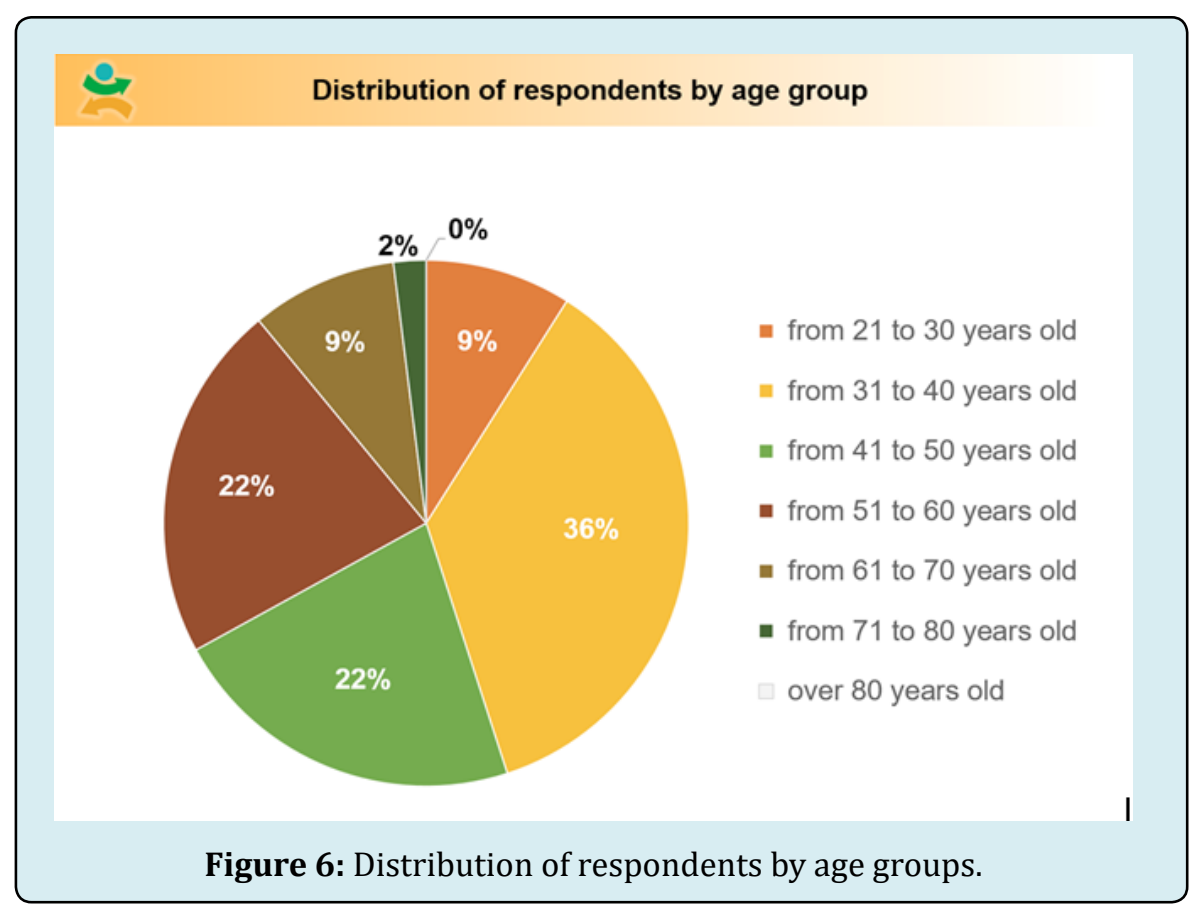

Thus, the data obtained from our platform shows a more expressive number of practices in the Southeastern region. Given that, by observing the strategic planning of IdeaSus, we strenghten the practice registration process in both the Northern and Northeastern regions, in view of the interface with Agenda 2030 embraced by Fiocruz, as well as several other key elements of our collaborative platform. In the Northern and Northeastern regions, health inequalities and inequities tend to worsen, because of the expenditure resolution (PEC55, 2016) implemented by the federal government.

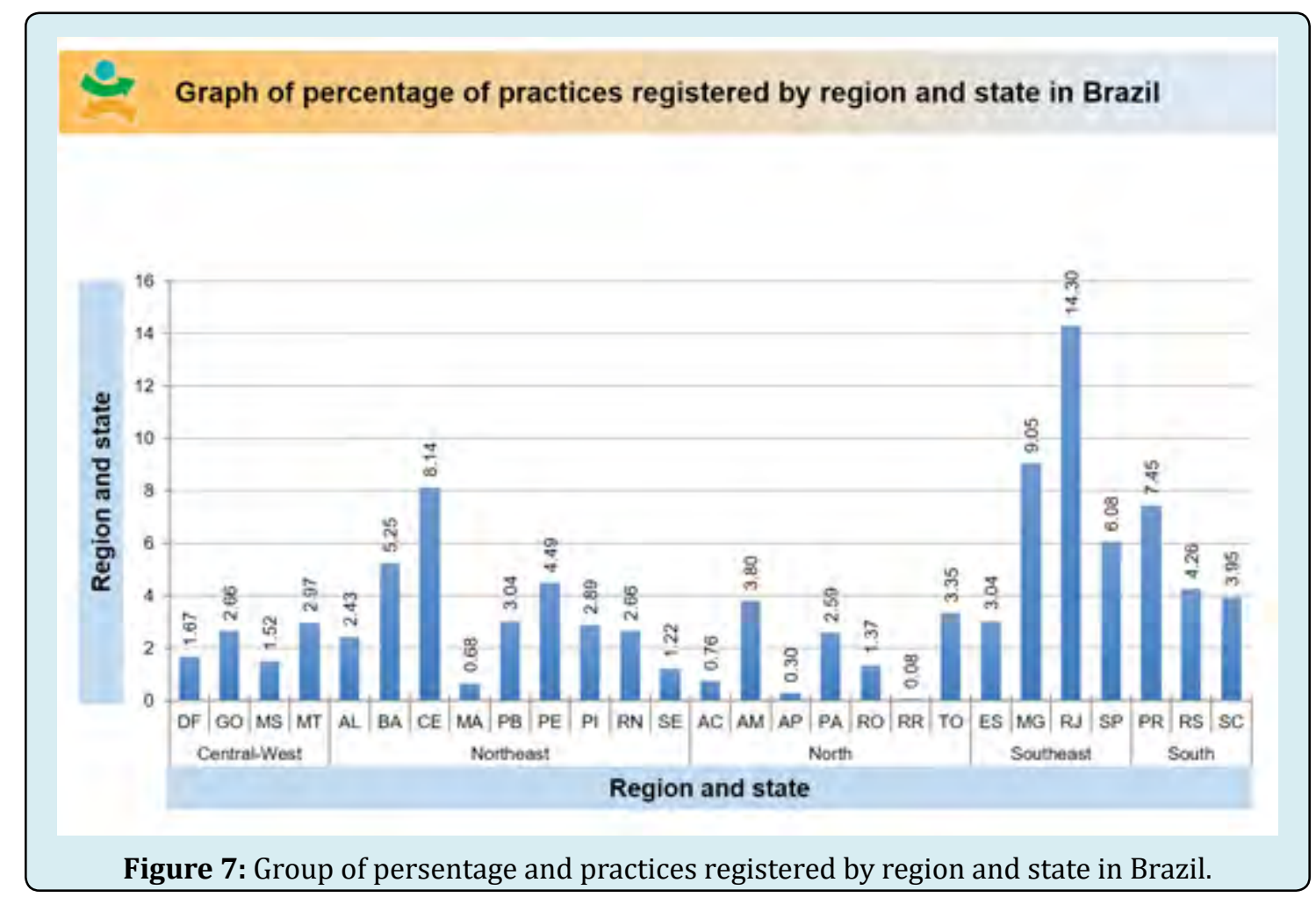


Based on the Report by Kastrup E, et al. CEE [13], the following is a table in which survey respondents rank the
SDGs in order of priority for implementation (pp: 13) (Figure 8).

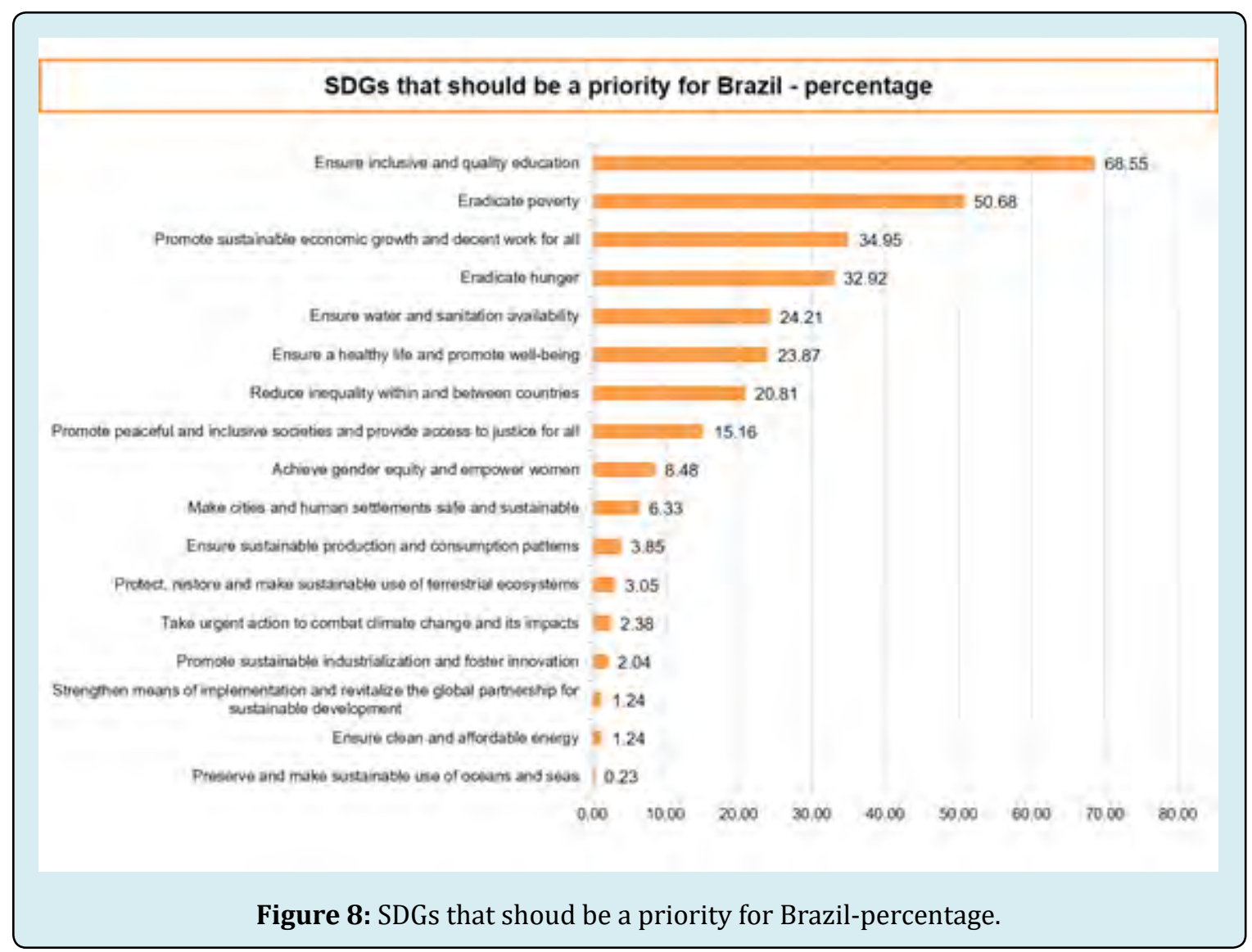

Supported by Almeida Filho, [14] who analyzed the importance of "critical technological competence in Health" in an Editorial at Interface, we state that:"[...] The practice of operators of health systems, policies, programs and services, in the near future, will require an inter-transdisciplinary, interprofessional, multi-referenced, culturally sensitive, politically responsible, quality-minded attitude [ ...]", for us to ask later:

"[...] Which knowledge, skills and abilities will be minimally needed? [...]"

That said, we keep in mind that the collaborative platform is only instrumental, a work tool, and that the incremental aspect must be grounded in "another kind of technology", that of relational character, a lightweight technology, as recommended by Merhy, et al. [15].

Following the same reasoning, as necessary as Jaime Breilh's [16] critical and emancipating epidemiology is Almeida Filho's, [14] consistent critique of a technocracy that moves away from relational technologies, which contribute to the perspective of health practices as a living act in the lines of comprehensive care.

Thus, we bet on methodologies that involve the subjects that are entitled to their health rights, spread throughout territories full of social inequalities and, consequently, health inequities.

Considering that, we propose that the IdeiaSUS platform, in addition to its repository dimension, behaves as a tool aligned with a process of territorial basis. This all considering its methodology of implication of subjects, a step towards the support to SUS territorial management. In these places, exchanges resulting from encounters between scientific and popular knowledge are capable of forming sustainable sociotechnical networks [16].

Based on Aquila Mendes, et al. [17], we believe that observing and understanding what is inscribed on Jaime Breihl's insignia is essential to achieve the goal of building a positive IdeiaSUS agenda at the interface with the SDGs:

"People are conditioned to live in a way that is not good 
for their health, with increasingly dangerous work systems, a waste-based consumer system, a way that is not protective of a buen vivir, but of a commercial consumption, deprived of defense resources and support of collective and community protective organizations" (pp: 83).

This leads us to propose that a set of goals and strategic objectives for IdeiaSUS necessarily involves strengthening the methodologies of dialogical exchanges, as well as the systematization of territorial/local experiences, as part of the same work process, providing the protagonists of these meetings with locoregional reflections on their practices.

Thus, the rounds of conversation would function as triggering devices, as social technologies that are inscribed as part of another type of territorial cartography, wherein certain practices address and reflect solutions about the health needs of the population, professionals and health managers.

However, in addition to their instrumental and methodological character, these rounds also provide opportunities for the development and strengthening of curatorial practices. In a second moment, this strengthening would enable the publication of thematic axes in the IdeiaSUS Magazine, to be published every six months on our platform. This, in addition to adding value to professional and popular practices, would consolidate the collaborative portfolio across different communities of existing practices.

Finally, among utopias and realities in Latin America [18], the cartography of practices and their respective territorialization in IdeiaSUS, as well as the virtual bank, can progressively constitute a space in which researchers from various areas can collect and research data about initiatives that seek to address health inequities throughout the country.

\section{Results}

As stated previously, this paper represents a literature review regarding the collaborative work of the community of practices within IdeiaSUS, a FIOCRUZ initiative, associated with CONASS and CONASEMS. If we dwell only on a few statistics relating to the expansion of the IdeiaSUS Platform, leaving aside socio-historical and political aspects that surround us, we may get feel optimist too early.

More than ever, there is a need to think locally of an ethical and political scenario, which is beyond conservative, with a clear lack of investment in strategic areas, such as health, education, science and technology.

We have about 1710 registered practices in IdeiaSUS, mostly in the Southeastern and Southern regions, whereas the Northern and Northeastern regions are still secondary. In the 2018/2019 biennium, we held about 15 rounds of conversation, which help to maximize the registration of new practices in different regions of the country of these, only 14.5 percent are still concentrated in the regions with the highest record, indicating that the Fiocruz/Conass/ Conasems partnership should focus its efforts and initiatives in the North and Northeast in the coming years, whether by conducting thematic rounds or training, analyzing the axes and filters that need to be strengthened.

Thus, the systematic analysis of the IdeiaSUS database should redirect strategic planning from its programmatic view, without losing sight of the fact that current socioeconomic and political aspects point to an aggravation of health policies.

The rise in measles cases $(8,600$ only in São Paulo State) and the fall in immunization coverage in the country need to be better understood; the stagnation of sanitation policies and the reduction of income redistribution programs and the decentralized provision of health care in more remote regions with the termination of the More Doctors Program (Programa Mais Médicos) reveal a reality that presents new challenges for the IdeiaSUS team for the years to come.

Mapping and systematization efforts must be intensified just like the risks of maximizing a social crisis unprecedented in the country's history, with over 13 million unemployed people; the increase in the hunger map and the end of social programs that once again put large shares of the population at risks and vulnerabilities. Not to mention that climate change will contribute to desertification, will increase migration and the tendency of violence in large cities.

Maintaining the achievements of SUS as a Universal system is fundamental, but we know that it is equally necessary to strengthen it seen the (ultra) neoliberal conservatism phenomenon that is advancing in Latin America, as a reflection of its progress throughout Europe. More than ever, the flag of the fight "Health is Democracy" is very current.

Our advances are undeniable, but still insufficient before the ethical, political and economic crisis that surrounds us, when workers lose their rights, and the policies designed point to profit maximization and the bet on a fiscal model that rates the poorest and boosts the accumulation of capital among the richest. What are the impacts on the Unified Health System? Many know this answer, but measures continue to open spaces for a greater participation of the private sector to the detriment of the growth of the public budget and the increase in the efficiency of public expenditure, applying more and better resources with strategic and integrated 
planning, as well as greater participation of society.

Where are the necessary advances in Primary Care? What is the future of the Family Health Strategy? Where and how will the scarce health budget be invested? Will innovative AIDS and tuberculosis programs be affected? Will there be a greater use of resources in the prevention and treatment of neglected diseases, arboviruses and others that are still highly prevalent in Brazil? We have no answers to these questions. We must rethink how to act in such worrying scenarios.

Fleeing from what is "conservative", reaffirming Maffesoli, [19] conceptual view that it is in the alterity of meetings held by IdeiaSUS what the author calls "character of the social bond", the reason why we foresee ahead of IdeaSUS.

\section{Final Considerations}

Suspended and immersed in a "virtual reality", the rarefied encounters to this moment become more frequent when we bet on rounds of conversations that even before shoot content and anticipate the feelings of belonging that only the social bond provides.

If in addition to a "solution bank" we discover in each of us that the verticality of being in a "cyber space" on the other hand forces us to "keep our feet on the ground" in the places in which we belong territorially and existentially. Without that we are a just a few more points in a "virtual network", but we know we are much more than that.

We are, although distanced, a society that is present in the meetings "face to face", "shoulder to shoulder", creating and recreating social bonds, facing "shadows" with the lights that emerge from these powerful encounters provided by IdeiaSUS.

Therefore, as professionals, we seek territorial sociability, existential solidarity, making the rounds of conversation and training a new rite of initiation, to recognize in each other that we are many, more than we could ever assume or imagine.

Sharing during each meeting, different professionals, managers and users use "pertinent words make things quicker," Maffesoli, [19] adds (pp:28).

We may need to think about strengthening intersectoral public policies and interprofessional health education, but that is already a topic to further explore.

\section{References}

1. Baumann Z (1999) Globalização: As Consequências Humanas.

2. Fadel LCV, Barros MH (2013) O sujeito sanitário na perspectiva do direito. In Direito e Saúde Cidadania e Ética na Construção de Sujeitos Sanitários. pp: 27-52.

3. Machado LP, Cristina Keiko Yamaguchi CK (2017) Abordagem Brasileira sobre Comunidades de Prática: Estudos a partir de busca sistemática, I Congresso Sul Catarinense de Administração e Comércio Exterior.

4. Tatiana T (2012) After all, what is a community of practice?.

5. Santos S, Chaui M (2013) Direitos Humanos, democracia e Desenvolvimento.

6. Fernandes VR, Profeta da Luz Z, Amorim AC, Sergio JV, Vicente da Silva, et al. (2017) O Lugar da vigilância no SUS-entre os saberes e as práticas de mobilização social. 22(10): 3173-3181.

7. Gondim GMM, Monken M, Rojas Li, Barcellos C, Peiter P, et al. (2018) A organização do sistema e a territorialização. In: Miranda A, Barcellos C, Monken M, et al. (Eds.).

8. Teixeira RR (1997) Modelos comunicacionais e práticas de saúde. Interface (Botucatu) 1(1): 7-34.

9. Pereira RB (2009) Tecnologias Sociais-Caminhos para a Sustentabilidade. Rede de Tecnologia Social.

10. Avelino N (2018) Introdução: pensar a política com Foucault. In: O Pensamento Político de Michel Foucault, Avelino N, Vaccaro S, et al. (Eds.).

11. Merleau Ponty M (2009) O visível e o Invisível. Perspectiva SP.

12. Lévy P (1999) 0 que é o Virtual?. 34 ${ }^{\text {th }}$ (Edn.), pp: 157.

13. Kastrup E, Rasga M, Durovini B, Braga A (2018) Percepção de especialistas em Saúde sobre a Agenda 2030. Relatórios de Pesquisa Centro de Estudos Estratégicos (CEE) da Fiocruz sobre os Objetivos do Desenvolvimento Sustentável.

14. Almeida Filho N (2018) Competência tecnologia crítica em Saúde. 22(66): 667-671.

15. Merhy EE (2002) Saúde: a cartografia do trabalho vivo. 24(8): 1953-1957. 
16. Breilh J (2007) Epidemiologia Crítica-Ciência emancipadora e interculturalidade.

17. Mendes A (2019) História Política e pensamento epidemiológico: Breilh e economia política da saúde. Revista Guillermo de Ockham 17(1).
18. Amorim AC, Rangel VR, Sérgio JV, Vicente da Silva (2019) Health and Equity in Latin America: utopias and reality. Health Promotion International 34(S1): 1-19.

19. Maffesoli M (2014) Iniciação, arquétipos e pósmodernidade. In: Brasileira AA, Luzes e Sombra, et al. (Edn.), Vozes, Petrópolis. 